\title{
Interstitial high-dose-rate brachytherapy in locally advanced and recurrent vulvar cancer
}

\author{
Sylwia Kellas-Śleczka, MD, PhD!, Brygida Białas, MD, PhD!, Marek Fijałkowski, MD!, Piotr Wojcieszek, MD, PhD!, \\ Marta Szlag, MSc, PhD², Agnieszka Cholewka, MSc², Maciej Śleczka, PhD³, Zofia Kołosza, MSc ${ }^{4}$ \\ 'Brachytherapy Department, Maria Skłodowska-Curie Memorial Cancer Centre and Institute of Oncology, Gliwice Branch, ${ }^{2}$ Department \\ of Radiotherapy and Brachytherapy Planning, Maria Skłodowska-Curie Memorial Cancer Centre and Institute of Oncology, Gliwice Branch, \\ ${ }^{3}$ Institute of Mathematics, University of Silesia, Katowice, ${ }^{4}$ Department of Epidemiology and Silesia Cancer Registry, Maria Skłodowska-Curie \\ Memorial Cancer Centre and Institute of Oncology, Gliwice Branch, Gliwice, Poland
}

\begin{abstract}
Purpose: The aim of the study was to report our experience with high-dose-rate interstitial brachytherapy (HDRISBT) in locally advanced and recurrent vulvar cancer.

Material and methods: Between 2004 and 2014, fourteen women with locally advanced or recurrent vulvar cancer were treated using HDR-ISBT in our Centre. High-dose-rate interstitial brachytherapy was performed as a separate treatment or in combination with external beam radiotherapy (EBRT) (given prior to brachytherapy).

Results: Patients were divided into: group I $(n=6)$ with locally advanced tumors, stages III-IVA after an incisional biopsy only, and group II $(n=8)$ with recurrent vulvar cancer after previous radical surgery. In group I, median follow up was 12 months (range 7-18 months); 1-year overall survival (OS) was 83\%. Transient arrest of cancer growth or tumor regression was noticed in all patients but $4 / 6$ developed relapse. Median time to failure was 6.3 months (range 3-11 months). The 1-year progression-free survival (PFS) was 33\%. In group II, median follow up was 28 months (range 13-90 months). The 1-year and 3-year OS was $100 \%$ and $80 \%$, respectively. The arrest of cancer growth or tumor regression was achieved in all patients. In $4 / 8$ patients neither clinical nor histological symptoms of relapse were observed but $4 / 8$ women experienced relapse. Median time to failure was 31 months (range 13-76 months). The 1-year and 3 -year PFS was $100 \%$ and $62.5 \%$, respectively. Two patients (14.3\%) in group II had severe late toxicity (G3).

Conclusions: High-dose-rate interstitial brachytherapy is a well-tolerated treatment option in selected patients with advanced or recurrent vulvar cancer. It is a safe and effective treatment modality for advanced and recurrent vulvar cancer, yielding good local control with acceptable late treatment related side effects. In our study, patients with recurrent vulvar cancer had better results in HDR-ISBT treatment, probably because of the smaller tumor volume. This hypothesis should be verified in a larger group of patients.
\end{abstract}

Key words: advanced, brachytherapy, HDR, interstitial, recurrent, vulvar cancer.

\section{Purpose}

Locally advanced and recurrent vulvar cancer may present a serious therapeutic problem. It occurs predominantly in elderly patients with severe comorbidities that often restrict the surgical treatment options. Interstitial brachytherapy is one of the possible treatment modalities in selected patients. Vulvar cancer represents approximately $4-5 \%$ of all gynecological tumors $[1,2,3]$. It is usually classified into two groups: the first is associated with human papillomavirus (HPV) infection and usually occurs in younger patients; the second is not HPV associated and is observed mostly in elderly patients with 'lichen sclerosus' as a predisposing risk factor [2,4]. There are several histological types, whereas squamous cell carcinoma (SCC) is the most common $(95 \%)$ [4,5]. It occurs predominantly in postmenopausal women, and the age-specific incidence increases with age [5]. The prognosis is strongly correlated to lymph node involvement and the stage of the disease [4]. Almost $50 \%$ of patients have advanced disease at presentation [6].

The standard treatment for vulvar SCC is surgery. External beam radiotherapy (EBRT), brachytherapy, and chemotherapy are either adjuvant or standalone treatment options. Over the last 2 decades, the use of primary radiotherapy for patients with stage III-IVA vulvar cancer increased from $18 \%$ in 1988 to $30 \%$ by 2008 [7], but even in combined therapy, $10-20 \%$ of women with early-stage disease and $50-70 \%$ in advanced stages may 
return $[2,4,5,8]$. Local recurrences are the most frequent pattern of failure, while less common are those located in the groin [9]. They usually occur within two years after primary therapy. Re-excision is usually the treatment of choice for failures localized on the vulva [10]. However, this may present a problem, because the blood supply and lymphatic drainage after vulvectomy are often disturbed. This makes surgical procedures more complex and less successful [11]. Vulvar SCC, like other SCC, is sensitive to radiation. For many years it was believed that EBRT and brachytherapy in the vulvar region, while yielding good therapeutic outcome, are associated with significant toxicity $[6,11]$.

Brachytherapy is an optimal treatment option for primary and recurrent carcinomas of the vulva, especially in patients with serious comorbidities and contraindications for surgery. This allows for the delivery of a very high radiation dose to the tumor while sparing organs at risk. This is especially important for cases where the tumor is located close to dose-limiting organs.

At our Department, high-dose-rate interstitial brachytherapy (HDR-ISBT) has been performed for almost thirty years in selected patients with primary advanced or recurrent vulvar cancer. The introduction of computed tomography (CT) image-guided HDR-BT has allowed for 3D treatment planning, and has improved the delineation of target volumes. The aim of our study was to report our experience with HDR-ISBT in locally advanced and recurrent vulvar cancer.

\section{Material and methods}

Between 2004 and 2014, seventeen women with locally advanced or recurrent vulvar cancer were treated using HDR-ISBT at our Department. Fourteen patients with minimum 7 months follow up were included in a retrospective analysis. High-dose-rate interstitial brachytherapy was performed as a separate treatment or in combination with EBRT. External beam radiotherapy was given prior to brachytherapy.

Patients were divided into two groups: group I $(n=6)$ with locally advanced tumors stage III-IVA (1994 FIGO) after an incisional biopsy only, and group II $(n=8)$ with recurrent vulvar cancer after previous radical surgery. Fourteen patients underwent fifteen HDR-ISBT procedures (14/15): one woman (group II) had interstitial brachytherapy twice because of two recurrences: each in different areas on the vulvectomy scar, with a five year gap between the treatments.

Median age in groups I and II was 79.5 years (range: 64-88) and 57 years (range 45-85), respectively. In both groups there were patients with tumors located on the clitoris: one in each group. Before undergoing brachytherapy, women in both groups reported moderate to severe local pain, occasional bleeding, and recurring infections in the vulvar area. Women with tumors localized near the urethra and those after previous EBRT, complained of problems with urination. When the tumor was located close to the anus, painful defecation was noticed. Patients in group I complained of vulvar edema, and dry or patchy moist desquamation after EBRT (G1 and G2 according to RTOG/EORTC scale - Radiation Therapy Oncology Group/European Organization for Research and Treatment of Cancer).

All patients were disqualified from surgery because of the tumor size and location, previous undergone surgery, or comorbidities. Patient and tumor characteristic in Table 1. 5/6 patients in group I were disqualified from radical radiochemotherapy because of bad health condition, comorbidities, and advanced age. They underwent palliative EBRT (20 Gy in 5 fractions). 1/6 patient underwent incomplete radical radiochemotherapy (50 Gy from 66 Gy planned because of severe toxicity and tumor progression). In whole group of patients, the disease progressed and women complained of vulvar pain and bleeding. They were treated with analgesics and antihemorrhagics, but afflictions increased. Three patients refused renewed EBRT, two underwent two cycles of EBRT $20 \mathrm{~Gy}$ in 5 fractions. One woman underwent incomplete radical EBRT. All patients in group I were qualified to palliative brachytherapy and the interstitial option was chosen because tumors were thicker than $5 \mathrm{~mm}$.

In group II, two patients had HDR-ISBT given as a "boost" with EBRT (the first: 54 Gy with 4 cycles of cisplatin, and the second: $50.4 \mathrm{~Gy}$ ) and six had standalone brachytherapy (one had radical EBRT to regional lymph nodes). Previous treatment in both groups is shown in Table 1.

\section{Brachytherapy implant procedure}

All patients were hospitalized before the procedure. The implantation was performed under general anesthesia. The target volume was determined after clinical examination, transrectal and/or transvaginal ultrasound, $\mathrm{CT}$, or magnetic resonance imaging (MRI) scans. Whenever possible, flexible catheters were used to prepare the temporary implant, otherwise steel needles were used. Implants were done with the free hand technique (no template used) after Foley catheter insertion.

Catheters and needles were inserted into the tumor in a single plane with a healthy tissue margin of at least $5 \mathrm{~mm}$. The distance between the catheters/needles was 9-11 mm (Figures 1 and 2). Antibiotics and analgesics were prescribed if necessary. At the end of the treatment, the catheters were removed. The Foley catheter was removed the next day.

\section{Brachytherapy planning and dosimetry}

The treated volume was determined using clinical examination and preoperative imaging: transvaginal or transrectal ultrasound and, since 2011, CT or MRI scans.

High-dose-rate brachytherapy was performed with afterloading ${ }^{192}$ Ir source using microSelectron HDR (Nucletron, an Elekta Company, Elekta AB, Stockholm, Sweden). Before 2011, the treatment plans were calculated with PLATO BPS v14.2.6 (Nucletron, Veenendal, The Netherlands) based on fluoroscopic images. Since 2011, 3D treatment plans have been computed using the Oncentra MasterPlan version, 4.1 Brachytherapy TPS (Nucletron, an Elekta Company, Stockholm, Sweden). 
Table 1. Combined data of all patients $(n=14)$ with treatment details, pattern of failure, and final outcome

\begin{tabular}{|c|c|c|c|c|c|c|c|c|c|c|}
\hline Group & $\begin{array}{l}\text { Patient } \\
\text { number }\end{array}$ & $\begin{array}{c}\text { Primary } \\
\text { EBRT (total } \\
\text { dose/number } \\
\text { of fractions) }\end{array}$ & $\begin{array}{c}\text { Lymph node } \\
\text { involvement } \\
\text { Yes/No }\end{array}$ & Comorbidities & $\begin{array}{c}\text { Tumor } \\
\text { extent before } \\
\text { brachytherapy }\end{array}$ & $\begin{array}{c}\text { Brachytherapy } \\
\text { total dose/ } \\
\text { Number of } \\
\text { fractions }\end{array}$ & $\begin{array}{l}\text { Number } \\
\text { of cathe- } \\
\text { ters (C)/ } \\
\text { Needles }(\mathrm{N})\end{array}$ & $\mathrm{V}_{100} \mathrm{~cm}^{3}$ & $\begin{array}{l}\text { Pattern } \\
\text { of } \\
\text { failure }\end{array}$ & $\begin{array}{l}\text { Alive } \\
\text { Yes/No }\end{array}$ \\
\hline \multirow{6}{*}{ 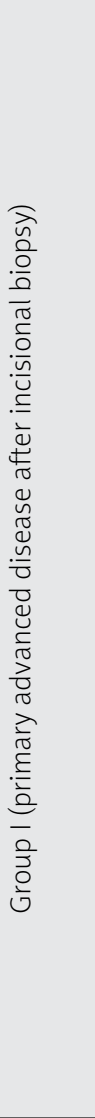 } & 1 & 20 Gy/5 & No & $\begin{array}{l}\text { AH, MI, } \\
\text { second } \\
\text { cancer }\end{array}$ & $\begin{array}{l}\text { Right labia } \\
\text { majora }\end{array}$ & 42 Gy/12 & $3 C$ & 13.4 & M & No \\
\hline & 2 & $2 \times 20 G y / 5$ & No & $\mathrm{AH}, \mathrm{DM}, \mathrm{MI}$ & $\begin{array}{c}\text { Right labia } \\
\text { majora and } \\
1 / 2 \text { left infil- } \\
\text { trating mons } \\
\text { pubis }\end{array}$ & 35 Gy/10 & $4 C$ & 40.1 & $L P$ & No \\
\hline & 3 & $2 \times 20 \mathrm{~Gy} / 5$ & No & DM & $\begin{array}{l}\text { Right and } \\
\text { left labia } \\
\text { majora and } \\
\text { perineum }\end{array}$ & 34.6 Gy/9 & $5 C$ & 38.1 & $L P$ & No \\
\hline & 4 & $\begin{array}{c}20 \text { Gy/5 } \\
\text { and } 20 \text { Gy/5 } \\
\text { on regional } \\
\text { lymph nodes }\end{array}$ & Yes & $\mathrm{AH}, \mathrm{DM}, \mathrm{MI}$ & $\begin{array}{l}\text { Right and } \\
3 / 4 \text { left labia } \\
\text { majora and } \\
\text { perineum }\end{array}$ & 35 Gy/10 & $7 C$ & 30 & $L P$ & No \\
\hline & 5 & $\begin{array}{c}20 \text { Gy/5 } \\
\text { and } 20 \text { Gy/5 } \\
\text { on regional } \\
\text { lymph nodes }\end{array}$ & Yes & $\mathrm{AH}, \mathrm{MI}$ & $\begin{array}{l}\text { Left and } \\
\text { right labia } \\
\text { majora with } \\
\text { perineum }\end{array}$ & 31.5 Gy/9 & $8 C$ & 58.7 & $\mathrm{RP}$ & Yes \\
\hline & 6 & $\begin{array}{l}50 \text { Gy/25 } \\
\text { (planned } \\
66 \text { Gy) on } \\
\text { vulva and } \\
\text { regional } \\
\text { lymph } \\
\text { nodes and } \\
\text { chemotherapy }\end{array}$ & Yes & $\mathrm{AH}$ & $\begin{array}{l}\text { Left labia } \\
\text { majora } \\
\text { infiltrating } \\
\text { clitoris }\end{array}$ & 32 Gy/10 & $3 C$ & 11.9 & M & No \\
\hline \multirow{5}{*}{ 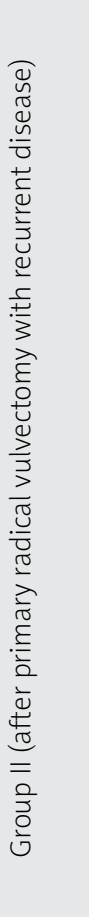 } & 7 & $\begin{array}{c}54 \text { Gy/27 } \\
\text { and chemo- } \\
\text { therapy }\end{array}$ & Yes & & $\begin{array}{l}\text { In postop- } \\
\text { erative scar } \\
\text { on left side } \\
\text { infiltrating } \\
\text { vagina }\end{array}$ & 24.5 Gy/7 & $3 C$ & 8.3 & LC & Yes \\
\hline & 8 & 50.4 Gy/28 & Yes & $\mathrm{AH}, \mathrm{MI}$ & $\begin{array}{l}\text { Left side of } \\
\text { a postopera- } \\
\text { tive scar }\end{array}$ & 15 Gy/5 & $3 C$ & 7.6 & LC & Yes \\
\hline & 9 & - & No & $\mathrm{AH}, \mathrm{MI}$ & $\begin{array}{c}\text { Near } \\
\text { postoperative } \\
\text { scar on left } \\
\text { side }\end{array}$ & $21 \mathrm{~Gy} / 3$ & $3 N$ & 4 & $L P$ & No \\
\hline & 10 & $\begin{array}{l}45 \text { Gy to } \\
\text { regional } \\
\text { lymph } \\
\text { nodes } \\
\text { plus } 10 \text { Gy } \\
\text { "boost" to } \\
\text { metastatic } \\
\text { nodes }\end{array}$ & Yes & DM & $\begin{array}{c}\text { Tumor in left } \\
\text { postoperative } \\
\text { scar } \\
\text { infiltrating } \\
\text { clitoris }\end{array}$ & 30 Gy/3 & $5-7 \mathrm{~N}$ & 39.4 & $\mathrm{RP}$ & No \\
\hline & 11 & - & No & & $\begin{array}{c}\text { Close to } \\
\text { postoperative } \\
\text { scar on left }\end{array}$ & $39.6 \mathrm{~Gy} / 12$ & $4 C$ & 6.6 & LC & Yes \\
\hline
\end{tabular}


Table 1. Cont.

\begin{tabular}{|c|c|c|c|c|c|c|c|c|c|c|}
\hline Group & $\begin{array}{l}\text { Patient } \\
\text { number }\end{array}$ & $\begin{array}{c}\text { Primary } \\
\text { EBRT (total } \\
\text { dose/number } \\
\text { of fractions) }\end{array}$ & $\begin{array}{l}\text { Lymph node } \\
\text { involvement } \\
\text { Yes/No }\end{array}$ & Comorbidities & $\begin{array}{l}\text { Tumor } \\
\text { extent before } \\
\text { brachytherapy }\end{array}$ & $\begin{array}{c}\text { Brachytherapy } \\
\text { total dose/ } \\
\text { Number of } \\
\text { fractions }\end{array}$ & $\begin{array}{c}\text { Number } \\
\text { of cathe- } \\
\text { ters (C)/ } \\
\text { Needles }(\mathrm{N})\end{array}$ & $\mathrm{V}_{100} \mathrm{~cm}^{3}$ & $\begin{array}{l}\text { Pattern } \\
\text { of } \\
\text { failure }\end{array}$ & $\begin{array}{l}\text { Alive } \\
\text { Yes/No }\end{array}$ \\
\hline \multirow{3}{*}{ 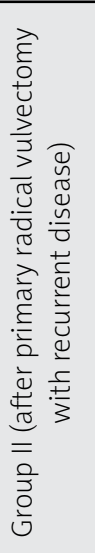 } & 12 & - & No & $\mathrm{AH}, \mathrm{DM}$ & $\begin{array}{l}\text { In postoper- } \\
\text { ative scar on } \\
\text { left infiltrat- } \\
\text { ing perineum }\end{array}$ & 43.4 Gy/13 & $4 \mathrm{C}$ & 11 & $\mathrm{RP}$ & No \\
\hline & 13 & - & No & & $\begin{array}{l}\text { In postoper- } \\
\text { ative scar on } \\
\text { left infiltrat- } \\
\text { ing perineum }\end{array}$ & 36 Gy/13 & $3 C$ & 9.3 & $L P$ & Yes \\
\hline & $14^{*}$ & - & No & & $\begin{array}{c}\text { Tumor in } \\
\text { postoperative } \\
\text { scar on left } \\
\text { Tumor in } \\
\text { postoperative } \\
\text { scar on right }\end{array}$ & 31.5 Gy/9 & $3 C$ & 10.8 & $\begin{array}{l}\mathrm{LC} \\
\text { twice }\end{array}$ & No \\
\hline
\end{tabular}

*Treated twice - both recurrences with HDR-ISBT

EBRT - external beam radiotherapy, $A H$-arterial hypertension, DM - diabetes mellitus, $M I$ - myocardial ischemia, $C$-catheters, $N$-needles, $V_{100}$ - volume receiving $100 \%$ of the prescribed dose, $L P$ - local progression, $R P$ - regional progression, $L C$ - local control, $M$ - metastases
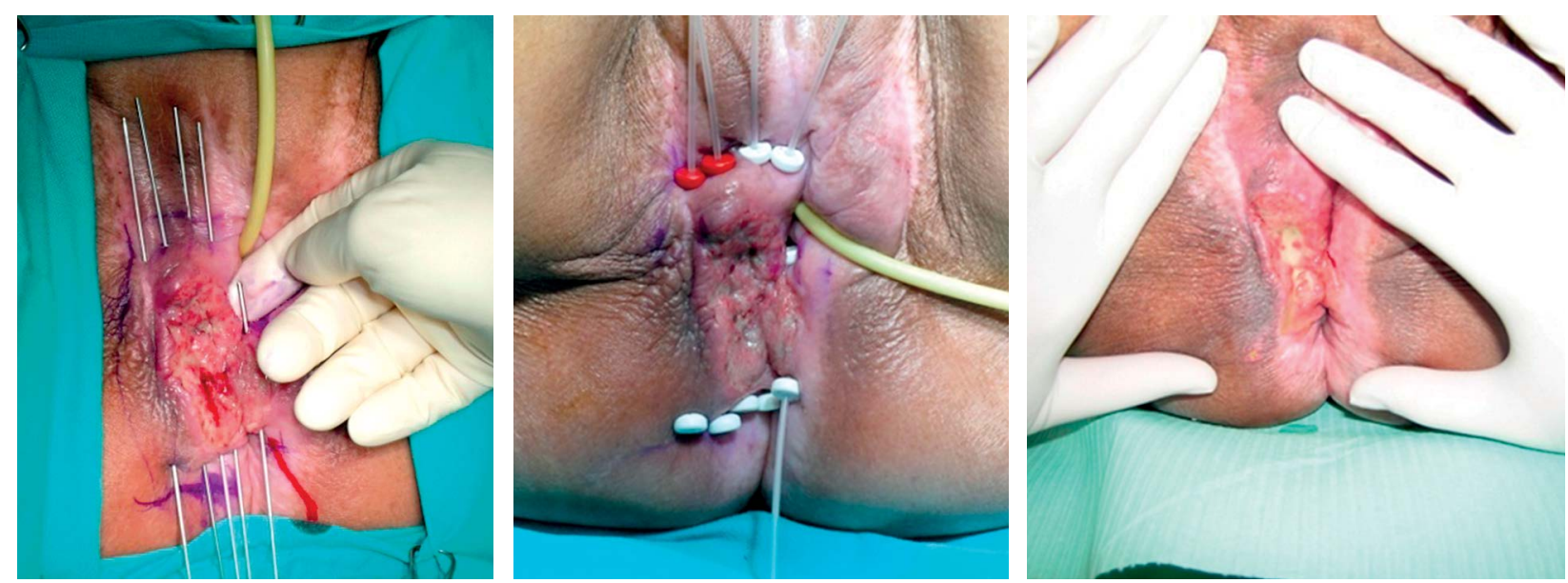

Fig. 1. High-dose-rate interstitial brachytherapy procedure

Cone beam CT imaging (Simulix Evolution, Nucletron, Veenendal, The Netherlands) was used for dose distribution calculation. Planning CT scans of the implant area were done with slice thickness of $1 \mathrm{~mm}$. The HDRISBT dose was prescribed at 4-6 $\mathrm{mm}$ from the applicator surface. In flexible catheter implants, the fractionation dose range was 3-3.7 Gy given twice a day with at least six hours interval between the fractions. The first fraction was given the same day the catheters were inserted. Usually, the first fraction was $5 \mathrm{~Gy}$. For the patients in whom needles were used, the dose range was 7-10 Gy per fraction, given once a week. If needed, both graphic and geometric optimization were done to achieve the optimal plan. The volumes receiving $90 \%$ $\left(\mathrm{V}_{90}\right), 100 \%\left(\mathrm{~V}_{100}\right), 150 \%\left(\mathrm{~V}_{150}\right)$, and $200 \%\left(\mathrm{~V}_{200}\right)$ of the prescribed dose were calculated. The most important organ at risk was the urethra. To evaluate the dose delivered to this organ, $\mathrm{D}_{2 \mathrm{cc}}$ and $\mathrm{D}_{0.1 \mathrm{cc}}$ were calculated based on the dose volume histogram derived from 3D dose distribution (Figure 3). Detailed HDR-ISBT treatment is shown in Table 2. The equivalent dose in $2 \mathrm{~Gy}$ fractions (EQD2) was calculated by using the following formula:

$$
\mathrm{EQD} 2=\mathrm{D}(\mathrm{d}+(\alpha / \beta)) /(2+(\alpha / \beta))
$$

where $D$ is the total dose, $d$ is the dose per fraction, and the $\alpha / \beta$ ratio is considered 10 for the tumor (Table 2).

The arrest of cancer growth or tumor regression at the site of origin was noticed in all patients. Time to progression, progression-free survival (PFS), overall survival (OS), and toxicity were analyzed. Time to progression was defined as the time in months from the ending of brachytherapy until objective tumor progression (local or regional recurrence and/or distant metastases). Local recurrence was defined as any recurrent disease in 


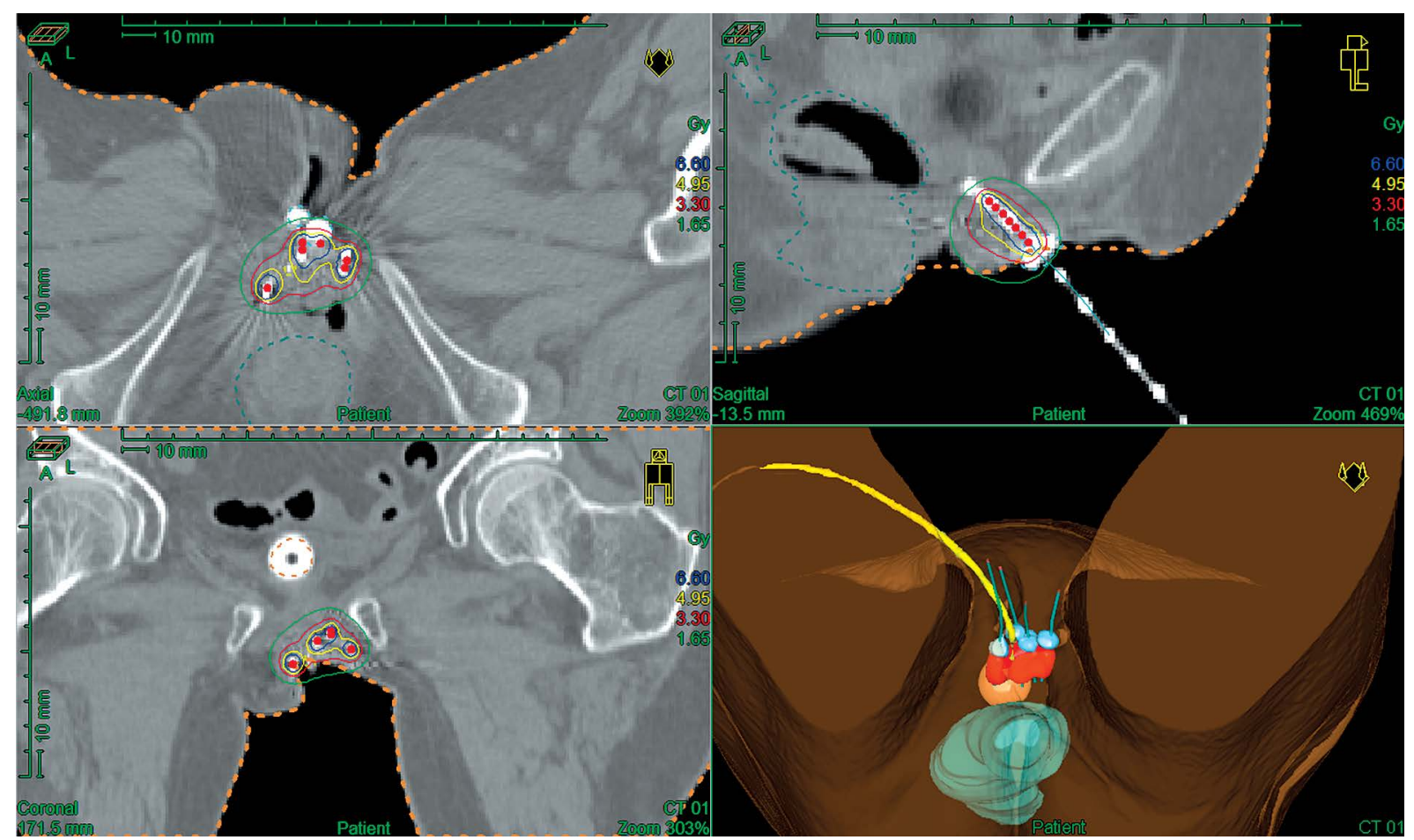

Fig. 2. High-dose-rate interstitial brachytherapy 3D treatment plan calculated on the basis of computed tomography. Urethra, catheter balloon, and rectum were delineated on computed tomography slices to evaluate the exposure to irradiation

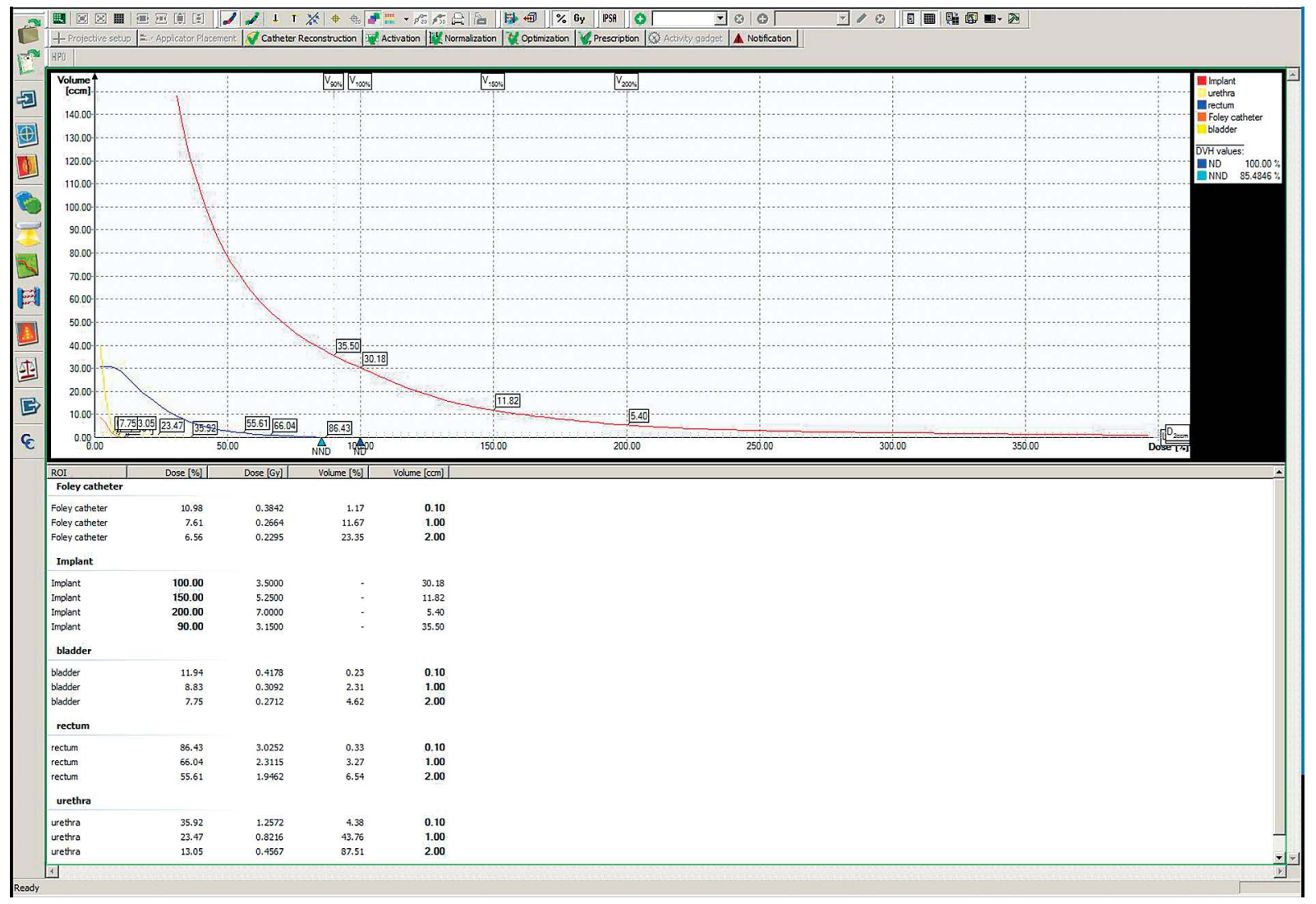

Fig. 3. Dose volume histogram 
the primary tumor site. The rest of the recurrences were qualified as regional (inguinal or pelvic region) or distant metastases. Progression-free survival was defined as the time between treatment initiation and tumor progression or death from any cause. Overall survival was defined as the period from the date of diagnosis to the date of death or last follow up.

Acute and late toxicity was graded according to the RTOG/EORTC scale.

\section{Statistical analysis}

The statistical software "Statistica 10" (StatSoft, Poland) was used for statistical analysis. Progression-free survival and OS were calculated using the Kaplan-Meier method.

Table 2. Interstitial high-dose-rate brachytherapy characteristic

\begin{tabular}{|c|c|c|}
\hline & Group I $(n=6)$ & Group II $(n=9)$ \\
\hline \multicolumn{3}{|l|}{ Implant } \\
\hline Flexible & 6 & 7 \\
\hline Needles & - & 2 \\
\hline \multicolumn{3}{|l|}{ Number of } \\
\hline catheters & 5 (range 3-8) & 3 (range 3-4) \\
\hline needles & - & 4 (range $3-7$ ) \\
\hline \multicolumn{3}{|l|}{ Implant parameters } \\
\hline$V_{90}$ & 40.5 & 9.9 \\
\hline$V_{100}$ & $34 \mathrm{~cm}^{3}(11.9-58.7)$ & $8.5 \mathrm{~cm}^{3}(4-39.4)$ \\
\hline$V_{150}$ & 14.2 & 4.4 \\
\hline$V_{200}$ & 7.3 & 2.1 \\
\hline \multicolumn{3}{|c|}{ ISBT fractionation dose } \\
\hline Catheters & $\begin{array}{l}\text { 3-3.7 Gy; first } \\
\text { fraction - } 5 \text { Gy }\end{array}$ & $\begin{array}{l}\text { 3-3.7 Gy; first } \\
\text { fraction - } 5 \text { Gy }\end{array}$ \\
\hline Needles & - & 7-10 Gy \\
\hline \multicolumn{3}{|l|}{ ISBT total dose } \\
\hline Boost & - & 19.8 Gy (15-24.5) \\
\hline $\begin{array}{l}\text { With palliative } \\
\text { EBRT }\end{array}$ & 35 Gy (31.5-42) & - \\
\hline Sole ISBT & - & 34.4 Gy (21-43.4) \\
\hline \multicolumn{3}{|l|}{ EQD2 } \\
\hline Boost & - & 22 Gy (16.3-27.6) \\
\hline $\begin{array}{l}\text { With palliative } \\
\text { EBRT }\end{array}$ & 39 Gy (34.6-45.5) & - \\
\hline Sole ISBT & - & 41 Gy $(29.7-50)$ \\
\hline ISBT treatment time & 5-16 days (m & dian 10 days) \\
\hline
\end{tabular}

$V_{90}$ - volume receiving $90 \%$ of the prescribed dose, $V_{100}$-volume receiving $100 \%$ of the prescribed dose, $V_{150}$ - volume receiving $150 \%$ of the prescribed dose, $V_{200}$-volume receiving $200 \%$ of the prescribed dose, ISBT - interstitial brachytherapy, EBRT - external beam radiotherapy, EQD2 - equivalent dose in 2 Gy fractions

\section{Results}

All patients completed the scheduled treatment without any interruption. In group I, median follow up was 12 months (range 7-18 months). 1-year OS was 83\% (Figure 4). Transient arrest of cancer growth at the site of origin was noticed in all patients. 5/6 women died within 18 months from the beginning of therapy. $3 / 6$ developed local and 1/6 - regional progression. 2/6 women died because of metastatic disease: one due to vulvar cancer and the second had a co-existent advanced tonsil carcinoma with lung metastases. Median time to failure was 6.3 months (range 3-11 months). One patient is still in follow up (10 months). She developed regional progression 6 months after brachytherapy (Table 1). The 1-year PFS in group I was 33\% (Figure 5).

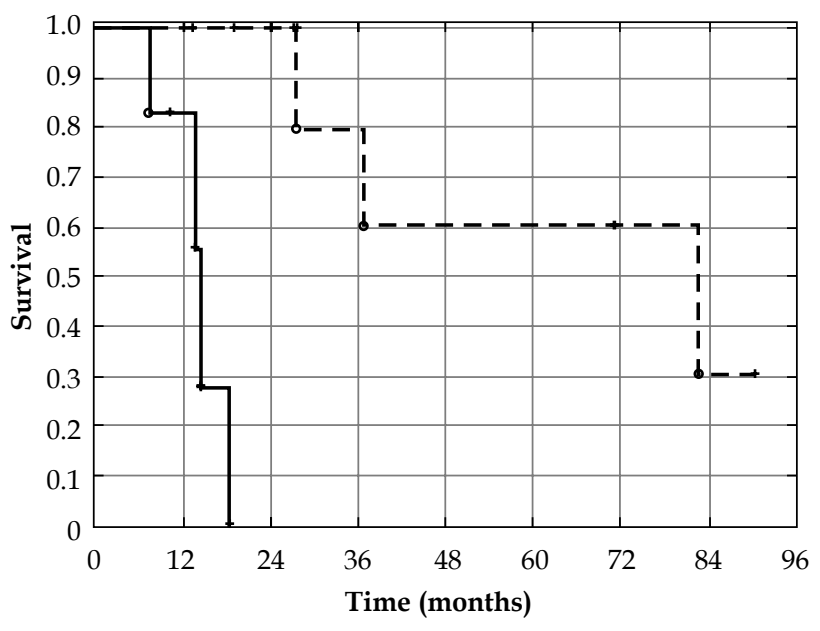

- Group I - - Group II

$$
p=0.013
$$

Fig. 4. Overall survival in both groups $(n=14)$. Group I $(n=6)$ with locally advanced vulvar cancer. Group II $(n=8)$ with recurrent vulvar cancer

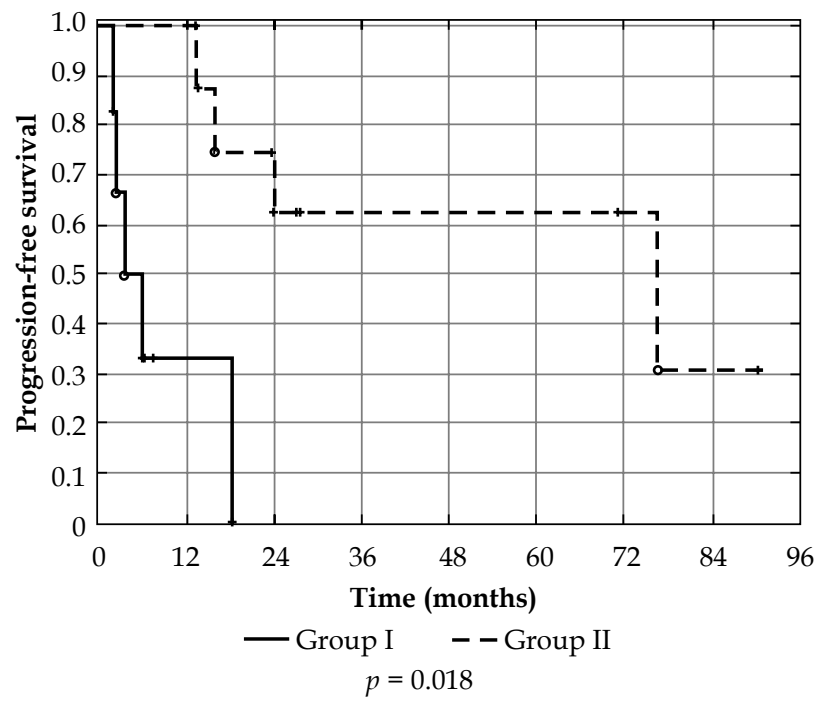

Fig. 5. Progression-free survival in both groups $(n=14)$. Group I $(n=6)$ with locally advanced vulvar cancer. Group II $(n=8)$ with recurrent vulvar cancer 


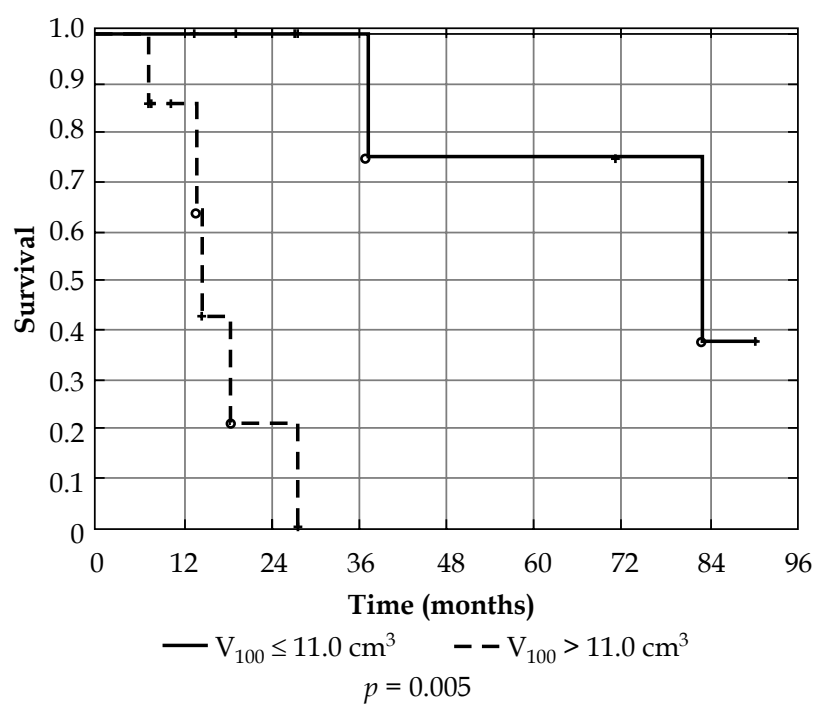

Fig. 6. Overall survival according to median $\mathrm{V}_{100}$. Median $\mathrm{V}_{100}=11.0 \mathrm{~cm}^{3}$

In group II, median follow up was 28 months (range 13-90 months). The 1-year and 3-year OS were $100 \%$ and $80 \%$, respectively (Figure 4). The arrest of cancer growth or tumor regression was achieved in all patients. In $4 / 8$ patients (5/9 cases) there were neither clinical nor histological symptoms of relapse during the last control: $3 / 4$ are alive and followed up, and 1/4 (treated with HDR-ISBT twice on each target within 7 and 2 year follow up) died because of myocardial infarcts. The next $4 / 8$ patients experienced relapse $-3 / 4$ died because cancer progression: $1 / 3$ due to local and $2 / 3$ regional recurrence. One patient with local recurrence is under surveillance. Median time to failure was 31 months (range 13-76 months) (Table 1). The 1-year and 3-year PFS was 100\% and $62.5 \%$, respectively (Figure 5). Significant differences in OS according to median $\mathrm{V}_{100}\left(11 \mathrm{~cm}^{3}\right)$ were observed $(p<0.02)$. Tumor volume smaller than median resulted in improved OS (Figure 6). There were no complications during the implantation. The treatment was well tolerated by all patients. In both groups acute toxicity predominantly included vulvar edema and radiation mucositis, which dissolved within 6-8 weeks after the treatment. These symptoms occurred mainly within 4 days and healed usually within 12 weeks. All women reported mild to moderate vulvar area pain. Two patients (14.3\%) in group II had severe late toxicity (G3), namely soft tissue necrosis. One of them died because of regional cancer progression. The second is under surveillance without active disease. Skin necrosis occurred in the previously treated area. The first patient had tumor previously located on the clitoris. She reported to our department with recurrent vulvar cancer situated very close to the urethra. High-dose-rate interstitial brachytherapy on the vulvar tumor was performed (total dose $30 \mathrm{~Gy}$ in 3 fractions given once a week with steel needles) and EBRT to regional lymph nodes (45 Gy with a 10 Gy boost to a metastatic lymph node identified by fine needle aspiration). The second patient underwent HDR-ISBT as a boost with concomitant chemoradiotheray (EBRT: 54 Gy to the vulva and regional lymph nodes in 2 Gy fractions along with 4 cycles of cisplatin out of 6 planned; due to deteriorating blood parameters the remaining two cycles could not be administered).

\section{Discussion}

Vulvar cancer is usually diagnosed in advanced stages, as well as in elderly patients with severe comorbidities, making the treatment decisions difficult. Advanced age has been identified as a prognostic factor for survival in vulvar cancer [12]. In our study, the median age was 78 years. Our group was relatively small and not homogeneous but vulvar cancer is rare condition. Palliative ISBT was chosen only for individually qualified patients with advanced disease (group I) and selected patients with vulvar cancer local recurrence with salvage or curative intent. Patients in group I underwent previous EBRT but the disease progressed. They complained of persistent vulvar pain and bleeding. Some patients refused renewed EBRT, and others received earlier two courses of palliative or incomplete radical radiotherapy on the vulvar area. In spite of analgesic and antihemorrhagic treatment, patients complaints increased. Then the decision of palliative ISBT was made. The interstitial option was chosen because tumors were thicker than $5 \mathrm{~mm}$, and only interstitial treatment gave the possibility to fully cover the target volume. The short follow up in that group is a limitation of the study, however 5/6 patients died within 18 months after HDR-ISBT. One is under control with 10 months follow up. The number of publications covering interstitial brachytherapy for advanced or recurrent vulvar carcinoma is still limited $[11,13,14]$, and there are no established recommendations for vulvar cancer brachytherapy. According to American Brachytherapy Society guidelines for vaginal lesions, ISBT can be performed in tumors, which are approximately $0.5 \mathrm{~cm}$ thick $[15,16]$.

The standard treatment in vulvar cancer is surgery with optional adjuvant treatment when indicated [10]. However, even after combined therapy, vulvar cancer may recur [17]. The reported rate of tumor recurrence ranges from $15-37 \%[18,19]$, and some of them may be other independent primary lesions [20,21]. In vulvar squamous cell carcinoma, approximately $40-60 \%$ of failures develop within two years after the primary treatment and most of them are local [19]. It is estimated that about $10 \%$ of patients experience recurrence 5 or more years after diagnosis [22]. Loco-regional failure is an important risk factor for distant metastatic disease. Vulvar cancer recurrences often cannot be re-excised because of the proximity of the rectum, bladder, or urethra $[15,20,23]$. For patients with advanced or recurrent cancer who are not eligible for surgery, radiotherapy or radiochemotherapy is a beneficial treatment option [12,13,14,17]. In our group of patients, women with primary advanced tumors were qualified to palliative treatment except one with incomplete radiochemotherapy due to tumor progression. All patients in both groups were disqualified from surgical procedures because of tumor location, previous definite surgery, or comorbidities. 
Modern EBRT and brachytherapy with advanced equipment and precise treatment planning offers a highly conformal technique with low associated toxicity. Interstitial brachytherapy is in particular an effective, non-aggressive, and individualized therapy given in a short period of time. Even in large, advanced or recurrent tumors, ISBT allows the reduction of the dose to organs at risk with very high doses given directly to the tumor. This is particularly important in elderly patients with severe comorbidities and contraindications for surgical procedures. Interstitial brachytherapy provides good comfort, even in palliative treatment. It reduces treatment time and irradiated volume, thus offering relief in ulcerated and painful tumors [14,24]. This is especially important in patients who have undergone previous EBRT in the treated area [25].

In our group, all implants were inserted with the freehand technique. When most of the tumor was located on the vulva, particularly in the labia, plastic catheters were chosen to prepare a temporary implant. Flexible catheters offer better dose distribution and higher quality of treatment for patients. Interstitial brachytherapy given in a short time with a relatively small area of irradiation resulted in very good treatment tolerance, and all women completed the scheduled therapy without any interruption.

Interstitial brachytherapy in primary advanced disease allowed the achievement of palliative effects: reduced afflictions and transiently arrested growth of the tumor. In the group treated with salvage or curative intent, $50 \%$ of the patients had no clinical or histological symptoms of cancer after HDR-ISBT at the last control.

In our study, significant differences in OS according to median $V_{100}$ were observed. Smaller tumor volume resulted in improved OS. It is well described in literature that tumor volume has a great impact on treatment results and survival: larger tumors have worse prognosis $[19,25,26]$. Patients with primary advanced disease were older with severe comorbidities. They could not be treated with radical intention because of the delay before the first visit. Patients with recurrent disease were younger and they were in regular controls after previous treatment. This led to the diagnosis of recurrent disease at an early stage.

It is well known that failures usually occur during the first two years after previous treatment but in some cases they may appear as late as within five or more years. Sometimes three or more local recurrences are observed, and some of them may be other independent primary tumors, occurring especially in patients with diagnosed 'lichen sclerosus' [9]. Nicoletto et al. had $46 \%$ of the second local recurrences in his study [27], and Wooderlink et al. observed a second or further local failure in $72 \%$ of cases [9].

There is no standard treatment schedule in HDR-ISBT in vulvar cancer, and it is difficult to compare doses between the published studies because of the insufficient homogeneity of the groups. In our study, the total doses in both groups were similar (except patients with BT boost). In the available literature, HDR-ISBT doses range between 30-42 Gy as a standalone treatment [13] and
16-20 Gy in combination with EBRT [25]. Beriwal et al. investigated a group of patients with primary and recurrent vulvovaginal malignancy. Thirteen patients received ISBT and the median dose of HDR-ISBT was $18.75 \mathrm{~Gy}$ in five fractions (EQD2 21.5 Gy) in combination with EBRT. No acute early toxicity was observed. Two patients (11\%) developed grade 3/4 late toxicity (rectovaginal fistula and chronic vaginal ulceration) [28]. In our group grade 1 and 2 acute toxicity included vulvar edema and radiation mucositis and pain that was resolved within 6-8 weeks after the treatment. No grade 3 or 4 acute toxicity was observed. Severe late toxicity G3 occurred in two patients with recurrent vulvar cancer. It was persistent skin and soft tissue necrosis (ulceration). One of them died because of regional cancer progression. The second is in regular control without active disease. Skin necrosis developed within the previously treated area.

In our group, two patients had tumors located on the clitoris. Both of them died: one because of regional tumor progression and the other because of distant metastases. It is known that patients with vulvar SCC with clitoral involvement have a worse prognosis. Some authors observed more positive groin lymph nodes in patients with clitoral involvement, probably because of the size, invasion depth of the clitoral tumor, and more direct lymphatic drainage from the clitoris to groin nodes [18].

\section{Conclusions}

Interstitial HDR brachytherapy is a well-tolerated treatment option in selected patients with advanced or recurrent vulvar cancer. Interstitial HDR brachytherapy is a safe and effective treatment modality for advanced and recurrent vulvar cancer, yielding good local control with acceptable late treatment-related side effects. In our study, patients with recurrent vulvar cancer had better results in HDR-ISBT treatment, probably because of the smaller tumor volume. This hypothesis should be verified in a larger group.

\section{Disclosure}

Authors report no conflict of interest.

\section{References}

1. Witteveen PO, van der Velden J, Vergote I et al. Phase II study on paclitaxel in patients with recurrent, metastatic or locally advanced vulvar cancer not amenable to surgery or radiotherapy: a study of the EORTC-GCG (European Organization for Research and Treatment of Cancer - Gynecological Cancer Group). Ann Oncol 2009; 20: 1511-1516.

2. Olejek A, Kozak-Darmas I, Kellas-Ślęczka S et al. The usefulness of bacteriological screening in wound healing aspect after vulvectomy. Menopause Rev 2005; 1: 33-36 [Article in Polish].

3. Kellas-Ślęczka S, Białas B, Fijałkowski M et al. Radical interstitial HDR brachytherapy in treatment of recurrent vulvar cancer: a case study. Menopause Rev 2012; 4: 329-333 [Article in Polish].

4. Alkatout I, Schubert M, Garbrecht N et al. Vulvar cancer: epidemiology, clinical presentation, and management options. Int J Womens Health 2015; 7: 305-313. 
5. Hacker NF, Eifel PJ, van der Velden J. FIGO cancer report 2012. Cancer of the vulva. Int J Gynecol Cancer 2012; 119 (Suppl 2): S90-S96.

6. Amsbaugh MJ, Bhatt N, Hunter T et al. Computed tomography planned interstitial brachytherapy for recurrent gynecologic cancer. Brachytherapy 2015; 14: 600-605.

7. Sharma Ch, Deutsch I, Herzog TJ et al. Patterns of care for locally advanced vulvar cancer. Am J Obstet Gynecol 2013; 209: 60.e1-60.e5.

8. Reade CJ, Eiriksson LR, Mackay H. Systemic therapy in squamous cell carcinoma of the vulva: Current status and future directions. Gynecol Oncol 2014; 132: 780-789.

9. Woolderink JM, de Bock GH, de Hullu JA et al. Patterns and frequency of recurrences of squamous cell carcinoma of the vulva. Gynecol Oncol 2006; 103: 293-299.

10. Ghebre RG, Posthuma R, Vogel RI et al. Effect of age and comorbidity on the treatment and survival of older patients with vulvar cancer. Gynecol Oncol 2011; 121: 595-599.

11. Viswanathan AN, Pinto AP, Schultz D et al. Relationship of margin status and radiation dose to recurrence in post-operative vulvar carcinoma. Gynecol Oncol 2013; 130: 545-549.

12. Serkies K, Wysocka B, Emerich J et al. Salvage Hemipelvis Radiotherapy with Fertility Preservation in an Adolescent with Recurrent Vulvar Carcinoma. Gynecol Oncol 2002; 85: 381-383.

13. Micheletti L, Preti M. Surgery of the vulva in vulvar cancer. Best Pract Res Clin Obstet Gynaecol 2014; 28: 1074-1087.

14. Tewari K, Cappuccini F, Syed AM et al. Interstitial brachytherapy in the treatment of advanced and recurrent vulvar cancer. Am J Obstet Gynecol 1999; 181: 91-98.

15. Nandwani PK, Vyas RK, Neema JP et al. Retrospective analysis of role of interstitial brachytherapy using template (MUPIT) in locally advanced gynecological malignancies. J Cancer Res Ther 2007; 3: 111-115.

16. Glaser SM, Beriwal S. Brachytherapy for malignancies of the vagina in the 3D era. J Contemp Brachytherapy 2015; 7: 312-318.

17. Gadducci A, Tana R, Barsotti C et al. Clinico-pathological and biological prognostic variables in squamous cell carcinoma of the vulva. Crit Rev Oncol Hematol 2012; 83: 71-83.

18. Hinten F, van den Einden LCG, Cissen M et al. Clitoral involvement of squamous cell carcinoma of the vulva: Localization with the worst prognosis. Eur J Surg Oncol 2015; 41: 592-598.

19. Peiró L, Chiva A, González R et al. Utility of the PET/CT in vulvar cancer management. Rev Esp Med Nucl Imagen Mol 2014; 33: 87-92 [Article in Spanish].

20. Bosquet JG, Magrina JF, Gaffey TA et al. Long-term survival and disease recurrence in patients with primary squamous cell carcinoma of the vulva. Gynecol Oncol 2005; 97: 828-833.

21. Beriwal S, Demanes DJ, Erickson B et al. American Brachytherapy Society consensus guidelines for interstitial brachytherapy for vaginal cancer. Brachytherapy 2012; 11: 68 75.

22. Moore DH, Ali S, Koh WJ et al. A phase II trial of radiation therapy and weekly cisplatin chemotherapy for the treatment of locally-advanced squamous cell carcinoma of the vulva: A gynecologic oncology group study. Gynecol Oncol 2012; 124: 529-533.

23. De Ieso PB, Mullassery V, Shrimali R et al. Image-guided vulvovaginal interstitial brachytherapy in the treatment of primary and recurrent gynecological malignancies. Brachytherapy 2012; 11: 306-310.

24. Amsbaugh MJ, Bhatt N, Parker L et al. Reirradiation using interstitial brachytherapy for recurrent gynaecological cancer. Brachytherapy 2015; 14 (suppl 1): S17-S18.

25. Zolciak-Siwinska A, Bijok M, Jonska-Gmyrek J et al. HDR brachytherapy for the reirradiation of cervical and vaginal cancer: analysis of efficacy and dosage delivered to organs AT risk. Gynecol Oncol 2014; 132: 93-97.

26. Aragona AM, Cuneo NA, Soderini AH et al. An analysis of reported independent prognostic factors for survival in squamous cell carcinoma of the vulva: Is tumor size significance being underrated? Gynecol Oncol 2014; 132: 643-648.

27. Nicoletto MO, Parenti A, Del Bianco P et al. Vulvar cancer: prognostic factors. Anticancer Res 2010; 30: 2311-2317.

28. Beriwal S, Heron DE, Mogus $R$ et al. High-dose rate brachytherapy (HDRB) for a primary or recurrent cancer in the vagina. Radiat Oncol 2008; 13: 3-7. 